\title{
CHYLOTHORAX - A RARE COMPLICATION AFTER CARDIAC SURGERY (A CASE REPORT)
}

\author{
Jiř́ Mandák, Petr Habal, Milan Štětina, Jan Harrer
}

Charles University in Prague, Faculty of Medicine and University Hospital Hradec Králové, Czech Republic: Department of Cardiac Surgery

\begin{abstract}
Summary: Chylothorax is a rare but severe complication of cardiac surgery. The authors present the case of a 76-year-old woman suffering from ischemic heart disease, after coronary artery bypass grafting that included a left internal mammary artery pedicle graft. On the ninth postoperative day the left-sided fluidothorax developed. The results of biochemical analysis were consistent with the chyle. Combined treatment with pleural drainage and total parenteral nutrition was effective.
\end{abstract}

Key words: Chylothorax; Coronary artery bypass graft surgery; Internal mammary artery

\section{Introduction}

Chylothorax, lymphatic pleural effusion, is a rare but severe complication of cardiac surgery.

The symptoms of chylothorax are the same as in any fluidothorax of other etiology, and so are the findings on images (X-ray, CT, ECHO, MRI). However, the biochemical finding is typical. The effusion is a milky cloudy fluid with elevated levels of triacylglycerols (twice to eight times as much as in serum), low level of cholesterol, elevated lymphocyte count and presence of chylomicrons.

Clinical signs may be poor at the beginning, but later, with greater volume of fluid in the pleural cavity, dyspnoea becoming a dominating complaint. With a longer course of chylothorax malnutrition sequelae may develop due to loss of proteins, immunoglobulins, lipids, electrolytes and water $(5,10,12)$.

Causes of chylothorax (so-called spontaneous) include inborn developmental anomalies of lymphatic vessels (congenital chylothorax), certain tumors (lymphomas), infections (lymphadenitis, filariasis), specific inflammations (tuberculosis, sarcoidosis), liver cirrhosis, thrombosis of the subclavian vein or superior vena cava, or lymphangiomyomatosis.

Chylothorax (traumatic chylothorax) may also result from a complication of trauma from a blunt or penetrating injury to the chest, or from vigorous coughing or vomiting. Chylothorax has been described as a complication of surgery of the esophagus, larynx, lungs, mediastinum, heart or great vessels, as a complication of great vessel cannulation or translumbar angiography, or as a sequela of radiotherapy $(1,9,10,11)$.
Chylothorax is a very rare complication in cardiac surgery $(5,9,10,12)$. Kilic and colleagues have observed this complication in less than $0.1 \%$ of patients who underwent coronary artery bypass surgery (8). It may develop after a procedure in the anterior mediastinum, due to damage to aberrant lymphatic vessels (11) and the thymus, or to damage to the thoracic duct at preparation of the great vessels during surgery for coarctation of the aorta, aneurysm of the aorta, persistent ductus arteriosus and similar cases (1). Chylothorax after coronary surgery may presumably result from an impairment of lymphatic pathways during mammary artery preparation, especially the thoracic duct where it drains into the jugular - subclavian venous junction or collateral lymphatics, proximal to this junction.

\section{A Case Report}

A 76-year-old female patient was admitted to the hospital with ischemic heart disease (triple vessel disease, CCS III., EF 55 \%). She underwent an on-pump myocardial revascularization using mammaro-coronary bypass grafting from the pedicled left mammary artery to left anterior descending artery and two aorto-coronary grafts from the great saphenous vein to the left marginal artery (obtuse branch) and right coronary artery.

The operation and postoperative course were standard without complications. The patient was extubated on the operation day and transfered from the intensive care unit on the second postoperative day. Perioperatively inserted drains were removed on the second postoperative day. There was no fluid drainage noted at that time. The patient 
presented no clinical problems, no dyspnoea and no fever during the next few days.

On routine examination before planned discharge, on the $9^{\text {th }}$ postoperative day, the follow-up chest X-ray showed a severe fluidothorax of the left pleural cavity (Fig. 1). After puncture, $1850 \mathrm{ml}$ of cloudy fluid was evacuated from the pleural cavity. The sample of the evacuated fluid was sent to the department of microbiology. Unfortunately no biochemical analysis was performed at that time.

On the following day, an additional $1500 \mathrm{ml}$ of milky effusion had to be removed by puncture from the pleural cavity. By biochemical analysis chylous fluid was diagnosed (triglyceride level of $14.52 \mathrm{mmol}^{-1}$ ) (Tab. 1). Microbiology revealed no growth on the third day. A thoracic drain was inserted in order to relieve the chylothorax, and subsequently a further $1000 \mathrm{ml}$ of chyle were evacuated.

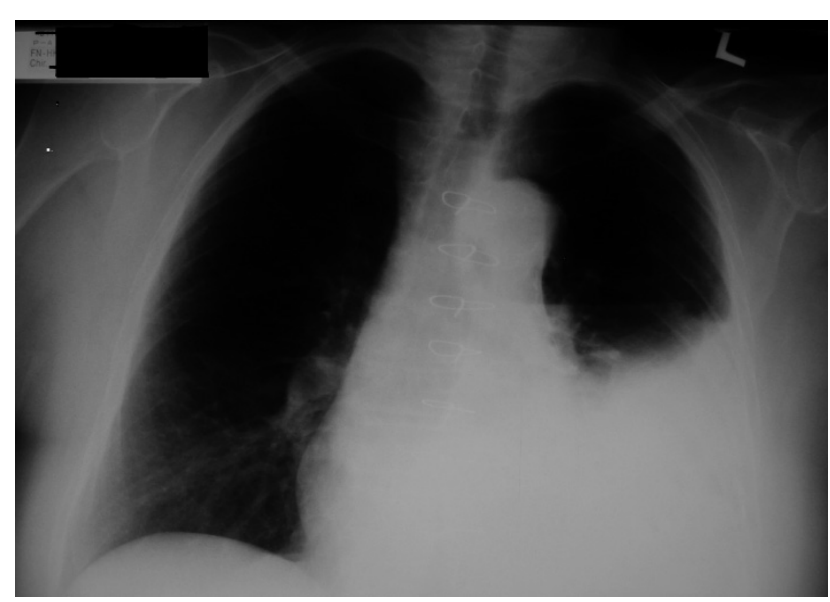

Fig. 1: Chest radiograph on the $9^{\text {th }}$ postoperative day showing left-sided pleural effusion.

Tab. 1: Laboratory data. The typical biochemical finding of chyle in pleural fluid.

\begin{tabular}{|l|c|c|}
\hline & Pleural fluid & Serum \\
\hline Triglyceride level $\left(\mathrm{mmol} . \mathrm{l}^{-1}\right)$ & 14.52 & 1.83 \\
\hline Total protein level $\left(\mathrm{g} . \mathrm{l}^{-1}\right)$ & 28.0 & 56.8 \\
\hline Cholesterol level $\left(\mathrm{mmol} . \mathrm{l}^{-1}\right)$ & 1.62 & 3.66 \\
\hline
\end{tabular}

Tab. 2: Total parenteral nutrition especially prepared for the patient for 1 day ("all-in-one") according to actual biochemical finding.

\begin{tabular}{|l|c|l|c|}
\hline Content-Nutrients & & Content-Preparations & $\mathrm{ml}$ \\
\hline $\mathrm{N}(\mathrm{g})$ & 15.61 & Neonutrin 15\% & 700 \\
\hline Lipids $(\mathrm{g})$ & 50.0 & Glukoza $40 \%$ & 700 \\
\hline $\mathrm{H} 2 \mathrm{PO} 4(\mathrm{mmol})$ & 18.0 & $\mathrm{NaCl} 0.9 \%$ & 1000 \\
\hline $\mathrm{Mg}++(\mathrm{mmol})$ & 12.2 & Lipofundin 20\% & 250 \\
\hline $\mathrm{K}+$ & 70.0 & KCl 7.45 \% & 70 \\
\hline $\mathrm{Na}+$ & 184.0 & Fosfat Natrium $8.7 \%$ & 60 \\
\hline Content $(\mathrm{ml})$ & 2810 & MgSO4 10\% & 30 \\
\hline
\end{tabular}

Energy 8476 kJ (2032 kcal), osmolality 1049.2 mOsm/L
Concurrently total parenteral nutrition $(8500 \mathrm{~kJ} /$ day $)$ was commenced (Table 2). The clinical condition of the patient remained stable, without subjective complaints. Biochemical laboratory data showed optimal concentrations of $\mathrm{Na}$ (137...139), K (4.8...4.5), Cl (101...104), urea (4.1...4,2),

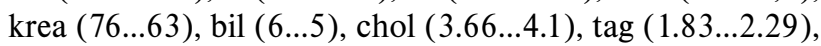
prot $(56.8 \ldots 68.4)$ and higher concentrations of ALT (0.72...0.77), AST (0.53 ...0.66) during the course of parenteral nutrition without any significant reaction to losses of chyle.

The losses from the thoracic drain gradually diminished

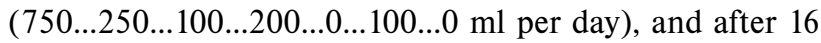
days it was possible to remove the pleural drainage. The total loss of chylous fluid reached $5750 \mathrm{ml}$. Follow up chest X-ray confirmed no reaccumulation of fluid. Complete diet was introduced gradually.

The patient was discharged home aftercare in a satisfactory condition on the $32^{\text {nd }}$ day. On the follow-up after one year, the patient was cardiopulmonary compensated, without complaints, and without pathologic findings in the pleural cavity.

The cause of this patient's chylothorax was not clear; it might have been due to damage to the thoracic duct, truncus mammarius or aberrant lymphatic vessels during preparation of the left mammary artery.

\section{Discussion}

Chylothorax is a rare complication of cardiac surgery. It usually forms two to five days after surgery when the patients start peroral diet (mainly high-fat diet). Early identification and prompt treatment may decrease both the early and the late morbidity and mortality. It was a bad mistake that no biochemical analysis was performed at the time of the first evacuation of pleural effusion in our patient.

The therapy of chylothorax is always combined - conservative and invasive.

The basis of conservative part of treatment of chylothorax is administration of a low-fat diet or, even better, total parenteral nutrition. The main goals are to minimize chyle formation and to prevent dehydratation, malnutrition, protein and electrolyte deficiencies, or immunosuppression (9, 10).

Excellent results are described after administration of octreotide, a synthetic long-acting somatostatin analogue which increases splanchnic arteriolar resistance and decreases the lymphatic flow. Octreotid administration may be used as the initial conservative therapy for moderate chylous drainage $(2,8)$.

Invasive therapy, an integral part of the treatment, is always based on evacuation of the pathological pleural fluid by means of puncture or by permanent chest drainage.

More aggressive surgical treatment is considered when the output remains high (>1000-1500 ml per day) despite the conservative management for a period more than 5 days, or if drainage or lung re-expansion is incomplete. This 
intervention is indicated by an assessment of each individual patient's condition. In many papers there is advocated the conservative management for maximum of 2 weeks period, where the indication for surgery is absent $(9,10)$. However, surgery for chylothorax can lead to a longer hospital stay, extra morbidity failure of the procedure, and high costs.

Lymphatic structures at the site of the defect may be treated by surgery (after thoracotomy or by means of videoassisted thoracotomy) by closure of the thoracic duct above the diaphragm (clipping, ligation, application of tissue glue). Thoracoscopic surgery may be the first choice $(8,13)$.

If this approach is not effective defects of lymphatic ways can be cloused by pleurectomy with pleurodesis and application of anti-inflammatory agents (biotalec, antibiotics) $(3,12)$. A pleuroperitoneal shunt could be indicated in high risk patients, with excessive chylous leak ( 2 week's duration, with output greater than $1000 \mathrm{~mL} /$ day) when preceding treatment was not successful (10).

Outstanding results have been described after application of percutaneous transabdominal embolization and blockage of lymphatic vessels (6). An effective result may be achieved after targeted radiotherapy (2). Others critically assess an importance of percutaneous strategy for diagnosing and treating chylothorax (3). These procedures should be attempted especially if patients are very ill, before more risk surgical thoracic duct closure is considered.

The applied combined therapeutic method - the evacuation of the fluid by permanent thoracic drainage and total parenteral nutrition was chosen in our patient. This therapeutic scheme resulted in decrese in chyle production, without any complications. We have chosen, to keep safe, this less invasive approach due to age of the patient, concomitant diseases and health status after the cardiac operation (less than 2 weeks). The patient is doing well without the recurrence 1 year after the procedure.

Though we already published an experience with 3 cases of chylothorax in the year 1988 (7), as we had met for the first time this complication after myocardial revascularization, we thought appropriate to dare to add even this rare case of chylothorax.

We recommend a combined treatment of chylothorax a drainage of pleural cavity and total parenteral nutrition for maximum of 2 weeks period. After it a surgical treatment is considered. Surgery or other intervention are indi- cated when the output remains high (> $1500 \mathrm{ml}$ per day) despite the conservative management for a period more than 5-7 days.

\section{Conclusion}

Chylothorax is a very rare complication of cardiac surgery. The real cause of its development in our patient after aorto-coronary bypass was not found. Presumably it was an injury to the lymphatic vessels (thoracic duct, truncus mammarius, aberrant pathways) at preparation of the mammary artery. The applied therapeutic method - the evacuation of the fluid by thoracic drainage and total parenteral nutrition was successful.

\section{Acknowledgements}

This article was financially supported by Research project MZO 00179906.

\section{References}

1. Allaham AH, Estrera AL, Miller CC, et al. Chylothorax complicating repairs of the descending and thoracoabdominal aorta. Chest 2006; 130: 1138-1142.

2. Barbetakis N, Xenikakis T, Efstathiou A, et al. Successful octreotide treatment of chylothorax following coronary artery bypass grafting procedure. A case report and review of the literature. Hellenic J Cardiol 2006; 47: 118-122.

3. Boffa DJ, Sands MJ, Rice TW, et al. A critical evaluation of percutaneous diagnostic and treatment strategy for chylothorax after thoracic surgery. Eur J Cardiothorac Surg 2008; 33(3): 435-439.

4. Charniot J, Zerhouni K, Kambouchner M, et al. Persistent symptomatic pleural effusion following coronary bypass surgery: clinical and histologic features, and treatment. Heart and Vessels 2007; 22(1): 16-22.

5. Choong CK, Martinez C, Barner HB. Chylothorax after internal thoracic artery harvest. Ann Thorac Surg 2006; 81: 1507-1509.

6. Cope C, Kaise LR. Management of unremitting chylothorax by percutaneous embolization and blockage of retroperitoneal lymphatic vessels in 42 patients. J Vasc Interv Radiol 2002; 13: 1139-1148.

7. Harrer J, Brzek V, Šimek J, et al. Chylothorax - problematika léčby. Rozhl Chir 1988; 67 (1): 27-31

8. Kilic D, Sahin E, Gulcan O, et al. Octreotide for treating chylothorax after cardiac surgery. Tex Heart Inst J 2005; 32(3): 437-439.

9. Light RW, Rogers JT, Moyers P, et al. Prevalence and clinical course of pleural effusions at 30 days after coronary artery and cardiac surgery. Am J Respir Crit Care Med 2002; 166: 1567-1571.

10. Nair SK, Petko M, Hayward MP. Aetiology and management of chylothorax in adult. Eur J Cardiothorac Surg 2007; 32: 362-369.

11. Naryan P, Rahaman N, Molnar TF, et al. Chylothorax following cardiac surgery caused by unusual lymphatic anatomy. Asian Cardiovasc Thorac Ann 2007; 15: $58-59$.

12. Pego-Frnandes PM, Ebaid GX, Nouer GH, et al. Chylothorax after myocardial revascularization with the left internal thoracic artery. Arg Bras Cardiol 1999; 73: 387-390.

13. Watanabe A, Koyanagi T, Nakashima S, et al. Supradiaphragmatic thoracic duct clipping for chylothorax through left-sided video-assisted thoracoscopic surgery. Eur J Cardiothorac Surg 2007; 31: 313-314

Received: 22/09/2010. Accepted in revised form: $21 / 11 / 2010$.

\section{Corresponding author:}

Jiří Mandák, MD, PhD, Associate Professor, Department of Cardiac Surgery, University Hospital, Sokolská 581,50005 Hradec Králové, Czech Republic; e-mail: jiri.mandak@centrum.cz 